\title{
The role of the cytomegalovirus antigenemia assay in the detection and prevention of cytomegalovirus syndrome and disease in solid organ transplant recipients: A review of the British Columbia experience
}

\author{
Erica D Greanya PharmD ${ }^{1,2}$, Nilufar Partovi PharmD FCSHP 1,2 , Eric M Yoshida MD FRCPC 3,4 , \\ R Jean Shapiro MD FRCPC ${ }^{3,5}$, Robert D Levy MD FRCPC ${ }^{3,6}$, Chris H Sherlock MD FRCPC ${ }^{3,7}$, \\ Gwen M Stephens MD FRCPC ${ }^{8}$
}

\begin{abstract}
ED Greanya, N Partovi, EM Yoshida, et al. The role of the cytomegalovirus antigenemia assay in the detection and prevention of cytomegalovirus syndrome and disease in solid organ transplant recipients: A review of the British Columbia experience. Can J Infect Dis Med Microbiol 2005;16(6):335-341.
\end{abstract}

BACKGROUND: The pp65 cytomegalovirus (CMV) antigenemia assay has been used as a means of guiding the pre-emptive therapy of CMV disease in solid organ transplant (SOT) recipients. Recently, concerns have been raised regarding the utility of the test to accurately and precisely detect viral activity early enough to reduce the morbidity and mortality associated with CMV.

OBJECTIVE: To determine the performance characteristics of the method of antigenemia testing of SOT recipients used at Vancouver General Hospital, Vancouver, British Columbia.

METHODS: All SOT recipients between January 1, 1999, and June 30, 2000, were retrospectively reviewed for six months following transplantation. Physical examination results, laboratory parameters, antigenemia results and treatment information were reviewed.

RESULTS: A total of 134 kidney, liver, lung and kidney-pancreas transplant recipients were included in the analysis. The overall performance characteristics of the antigenemia assay in predicting CMV disease included a sensitivity of $64 \%$, a specificity of $81 \%$, a positive predictive value of $76 \%$ and a negative predictive value of $71 \%$. A mean of 18 days passed between the onset of signs and symptoms of CMV disease/syndrome and the first recorded positive antigenemia result, and only $26 \%$ of patients had a positive test result before the onset of symptoms. It was found that an antigenemia test breakpoint of at least one positive cell for defining a positive test provided the most sensitive and specific prediction, with increased odds of developing CMV disease.

CONCLUSIONS: Based on performance characteristics, the Vancouver General Hospital's current method of antigenemia testing to guide pre-emptive ganciclovir therapy in SOT patients is not optimal for the early detection of disease. Further study is needed on new molecular testing methods to determine if our ability to predict CMV disease can be improved.

Key Words: Antigenemia; Cytomegalovirus; Solid organ transplantation
Rôle du dosage de l'antigène du cytomégalovirus dans le dépistage et la prévention du syndrome/ maladie à cytomégalovirus chez des receveurs de transplantation d'organes pleins : Survol de l'expérience acquise en Colombie-Britannique

HISTORIQUE : Le dosage de l'antigène pp65 du cytomégalovirus (CMV) a été utilisé pour guider le traitement préventif de la maladie à CMV chez des receveurs de transplantations d'organes pleins, et récemment, on s'est interrogé sur la véritable utilité du test à mesurer l'activité virale avec précision et justesse et ce, assez tôt pour réduire la morbidité et la mortalité associées au CMV.

OBJECTIF : Vérifier les caractéristiques et le rendement de la technique de dépistage de l'antigène du CMV utilisée chez les receveurs de transplantations d'organes pleins à l'Hôpital Général de Vancouver, Vancouver, Colombie-Britannique.

MÉTHODES : Tous les cas de greffes d'organes pleins entre le $1^{\text {er }}$ janvier 1999 et le 30 juin 2000 ont été examinés de façon rétrospective sur une période de six mois suivant la transplantation. Les résultats de l'examen médical, des analyses de laboratoire et du dosage de l'antigène et les données sur les traitements ont été passés en revue.

RÉSULTATS : En tout, 134 greffés du rein, du foie, des poumons ou du rein/pancréas ont été inclus dans l'analyse. Les caractéristiques de rendement globales du dosage de l'antigène pour ce qui est de prédire la maladie à CMV étaient notamment une sensibilité de $64 \%$, une spécificité de $81 \%$, une valeur prédictive positive de $76 \%$ et une valeur prédictive négative de $71 \%$. En moyenne, 18 jours se sont écoulés entre le déclenchement des signes et symptômes de la maladie ou du syndrome à CMV et le premier résultat d'antigénémie positif, et seulement $26 \%$ des patients présentaient un résultat positif aux tests avant le déclenchement des symptômes. On a découvert qu'un test d'antigénémie faisant état d'au moins une cellule (définition d'un test positif), constituait le facteur de prévisibilité le plus sensible et spécifique, et correspondait à une augmentation du risque à l'égard de la maladie à CMV.

CONCLUSIONS : Sur la base des caractéristiques de rendement, on considère que la méthode actuelle de dosage de l'antigène utilisée à l'Hôpital Général de Vancouver pour guider le traitement préventif par ganciclovir chez des receveurs de transplantations d'organes pleins n'est pas idéale pour le dépistage précoce de la maladie. Il faudra approfondir la recherche sur de nouvelles méthodes d'analyses moléculaires et vérifier de quelle manière il serait possible d'améliorer notre capacité de prédire la maladie à CMV.

${ }^{1}$ Pharmaceutical Sciences Clinical Service Unit, Vancouver General Hospital; ${ }^{2}$ Faculty of Pharmaceutical Sciences; ${ }^{3}$ Faculty of Medicine, University of British Columbia; ${ }^{4}$ Liver Transplant Program; ${ }^{5}$ Renal Transplant Program; ${ }^{6}$ Lung Transplant Program; ${ }^{7}$ Virology, British Columbia

Transplant Society; ${ }^{8}$ British Columbia Centre for Disease Control, Vancouver, British Columbia

Correspondence: Dr N Partovi, Pharmaceutical Sciences, Vancouver General Hospital, 855 West 12th Avenue, Vancouver, British Columbia

V5Z 1M9. Telephone 604-875-4293, fax 604-875-5267, e-mail Partovi@interchange.ubc.ca

Received for publication October 9, 2003. Accepted September 8, 2005 
C ytomegalovirus (CMV) remains a major cause of morbidity and mortality in solid organ transplant (SOT) recipients (1). Symptomatic CMV disease occurs in $8 \%$ to $39 \%$ of SOT recipients, depending on the type of transplant and degree of immunosupression (1-3). In addition to direct target organ disease caused by CMV, other examples of morbidity include increased risk of acute and chronic rejection, graft dysfunction and superinfection $(1,4,5)$. Prophylactic treatment with ganciclovir (GCV) has been used to decrease the incidence of CMV disease; however, GCV may also lead to unnecessary drug toxicity and the development of resistant strains (6). In recent years, the method of dealing with CMV disease has moved from universal prophylaxis to pre-emptive therapy, in which treatment is not administered until there is evidence of viral replication (7). Pre-emptive therapy reduces overall exposure of these patients to GCV by avoiding unnecessary treatment and by initiating therapy before significant morbidity and mortality secondary to CMV occur $(7,8)$.

Pre-emptive treatment strategies, however, require a rapid diagnostic test with high sensitivity that accurately predicts CMV disease (high positive predictive values [PPVs]). Several CMV diagnostic techniques, including shell vial culture to detect viremia, the antigenemia assay, and methods to detect DNAemia, such as the polymerase chain reaction (PCR) and hybrid-capture RNA-DNA assays, enable quantification of viral replication (9). Among these techniques, the pp65 antigenemia assay remains the most common method for monitoring transplant recipients for evidence of CMV disease (8). The CMV antigenemia assay quantifies the level of replicating virus by assessing the expression of the pp65 antigen in polymorphonuclear leukocytes (PMN). However, the exact number of antigen-expressing cells that should be treated as a positive test result is not uniform, with breakpoints for positive test results ranging from one cell per $200,000 \mathrm{PMN}$ to 50 cells per 200,000 PMN at different centres (10).

Although the pp65 antigenemia assay has been part of the pre-emptive CMV therapy protocol at Vancouver General Hospital (Vancouver, British Columbia) for several years, much controversy exists on its utility. The lack of evidence to define breakpoints of the test and conflicting evidence on the test's sensitivity and specificity in detecting CMV disease provide needed ammunition in the search for newer testing methods that may be more reliable. The primary objective of the present study was to evaluate the performance of our protocol of pp65 antigenemia testing in predicting CMV disease/syndrome in SOT recipients. Our secondary objectives were the determination of the antigenemia breakpoint, or number of positive cells that best correlated with CMV disease/ syndrome, and the evaluation of independent predictors of CMV infection.

\section{METHODS}

\section{Study design}

A single-centre, retrospective chart review was conducted to evaluate the test performance of CMV antigenemia as a tool to manage the pre-emptive therapy of significant CMV disease in SOT recipients. Charts were reviewed from the time of transplantation to six months post-transplantation. Assessment of baseline demographic and serological data was performed. Data collection from each outpatient follow-up visit included antigenemia test results, viral culture, biopsy results, physical examination and laboratory parameters, current antirejection regimens and data on GCV therapy. To determine the presence or absence of CMV disease/syndrome at the time of the visit, all physical examination information collected was retrospectively analyzed by two investigators who were blinded to each other's decisions. Discordant clinical interpretations were discussed and a consensus was reached.

\section{Study population}

All kidney, kidney-pancreas, liver and lung transplantations between January 1, 1999, and June 30, 2000, were screened for review. Before study initiation, approval was received from Vancouver General Hospital's ethical review board. Patients were excluded from review if they expired for reasons other than CMV disease, had graft failure within seven days after transplantation or were lost to follow-up within 30 days post-transplantation.

\section{CMV antigenemia test}

The present study used the CMV-Vue FITC kit (DiaSorin Inc, USA), which is based on immunocytochemical detection of the early structural, lower matrix protein (pp65) of CMV in peripheral blood PMNs. Within $6 \mathrm{~h}$ of collection, PMNs were isolated from the patient's blood by dextran separation and quantified in an improved Neubauer hemocytometer (Hausser Scientific, USA) according to the manufacturer's instructions. This was followed by incubation with a mixture of two different mouse monoclonal antibodies directed against pp65, and then with fluorescein isothiocyanate-labelled antimouse immunoglobulin $G$ conjugate. Positively stained cells were viewed by fluorescence microscopy and were expressed as the number of fluorescing cells per 200,000 PMNs.

\section{Prophylactic/pre-emptive CMV protocol}

As of January 1, 1999, Vancouver General Hospital has followed a set protocol for CMV management in all SOT patients. The prophylactic/pre-emptive protocol differs depending on baseline CMV serology of the donor and recipient, as well as the type of organ being transplanted. Prophylactic GCV therapy was administered to CMV-negative recipients who received a CMV-positive organ (ie, mismatch) and to CMV-positive patients who received antilymphocyte or antithymocyte preparations (muromonab-CD3 or antithymocyte globulin). In all other recipients, pp65 antigenemia testing was followed weekly from two to 16 weeks after transplantation without GCV prophylaxis. The CMV antigenemia threshold count for the start of therapy was varied depending on the transplanted organ. Pre-emptive therapy with GCV was initiated when antigenemia counts rose above prespecified breakpoints (ie, at least five cells per 200,000 PMN for liver and for CMVpositive lung recipients, at least four cells per 200,000 PMN for kidney and kidney-pancreas recipients, and at least three cells per 200,000 PMN for mismatch lung transplant recipients.

\section{Definitions of CMV disease/syndrome}

Definitions used to classify CMV disease and syndrome were derived from the Paris and Stockholm 1995 workshops on CMV disease (11). CMV pneumonia was defined as the presence of clinical symptoms of pneumonia with radiographic changes and/or hypoxemia, and detection of CMV in bronchoalveolar lavage or lung biopsy samples. Gastrointestinal disease was defined as the presence of gastrointestinal symptoms and the detection of CMV by histology or immune histochemistry in biopsies of macroscopic lesions found on endoscopy. Finally, CMV hepatitis-cholangitis was defined as having two times the upper limit of normal bilirubin or liver enzymes, histopathological confirmation of hepatitis, or cholangitis and CMV detection on liver biopsy. CMV syndrome 
TABLE 1

Patient demographics including cytomegalovirus (CMV) serology at time of transplantation $(n=134)$

\begin{tabular}{ll}
\hline Characteristic & \\
\hline Sex, $\mathrm{n}(\%)$ & $82(61)$ \\
Male & $52(39)$ \\
Female & \\
Transplant type, $\mathrm{n}(\%)$ & $78(58)$ \\
Kidney & $42(31)$ \\
Liver & $9(7)$ \\
Kidney-pancreas & $5(4)$ \\
Lung & $46.7(13-73)$ \\
Age, mean years (range) & \\
Baseline CMV serology, $\mathrm{n}(\%)$ & $23(17)$ \\
R-/D- & $86(64)$ \\
R+/D \pm & $25(19)$ \\
R-/D+
\end{tabular}

$D$ Donor CMV serology status; $R$ Recipient CMV serology status at time of transplantation (either positive [+] or negative [-] for CMV)

was suspected if antigenemia testing for CMV showed at least four cells per 200,000 PMN and if at least two of the following symptoms were present and unexplained by available diagnostic testing or known disease states: fever of at least $38^{\circ} \mathrm{C}$ (oral); new onset malaise or general symptoms of fatigue and weakness; leukopenia (white blood cell count less than $4 \times 10^{9} / \mathrm{L}$ ); thrombocytopenia (platelet count less than $125 \times 10^{9}$ cells/L); and liver enzymes 1.5 times the upper limit of normal (not considered in liver transplant recipients).

\section{Data analysis}

In determining the performance characteristics of the antigenemia assay, the gold standard was considered to be the clinical definitions of CMV disease/syndrome described above. Two-by-two tables were used to calculate sensitivity, specificity, PPVs and negative predictive values (NPVs). A receiver operating characteristic (ROC) curve analysis was performed for plausible thresholds of positivity for CMV antigenemia testing to determine the optimal cell number that would indicate a positive result. All univariate comparisons were unpaired and all tests of significance were twotailed. Continuous variables were compared by Student's $t$ test, with equal or unequal variance as determined by F-test analysis of each parameter. Categorical data were compared using $\chi^{2}$ or Fisher's exact test, depending on sample size. All continuous variables are expressed as means (range) and all categorical variables as percentages. $\mathrm{P} \leq 0.05$ was considered significant; however, variables with $\mathrm{P} \leq 0.10$ were tested in the regression models.

Multiple logistic regression was used to assess the strength of association of CMV disease/syndrome and the presence of each of the cutoff points for antigenemia. The odds ratio estimated by this technique expresses how likely it is that individuals who have the prespecified level of antigenemia develop CMV disease/syndrome. Transplant type and serology were added to the regression models as potential confounding factors. Interactions between terms were tested for significance. Statistical significance for differences between proportions were assessed by $\chi^{2}$ tests and, for logistic regression coefficients, the Wald $\chi^{2}$ test was used. $\mathrm{P}<0.05$ (twotailed) indicated statistical significance. The residuals were examined for violations of the assumptions of logistic regression. All analyses were performed using SPSS software (version 10, SPSS Inc, USA) for Windows (Microsoft Corporation, USA).
TABLE 2

Incidence of positive antigenemia (ie, one or more cells) and cytomegalovirus (CMV) disease/syndrome according to CMV serology and transplant type

\begin{tabular}{lccc}
\hline & $\begin{array}{c}\text { Antigenemia- } \\
\text { positive, } \\
\mathbf{n}(\%)\end{array}$ & $\begin{array}{c}\text { CMV disease/ } \\
\text { syndrome, } \\
\mathbf{n}(\%)\end{array}$ & $\begin{array}{c}\text { Ganciclovir } \\
\text { therapy initiated, } \\
\mathbf{n}(\%)\end{array}$ \\
\hline CMV serology & & & \\
R-/D- $(\mathrm{n}=23)$ & $0(0)$ & $3(13)$ & $1(4)$ \\
R+/D $(\mathrm{n}=86)$ & $42(49)$ & $45(52)$ & $22(26)$ \\
R-/D+ $(\mathrm{n}=25)$ & $12(48)$ & $16(64)$ & $5(20)$ \\
Total $(\mathrm{n}=134)$ & $54(40)$ & $64(48)$ & $28(21)$ \\
$\mathrm{P}^{*}$ & 0.05 & 0.001 & 0.084 \\
Transplant type & & & \\
Kidney and kidney- & $34(39)$ & $36(41)$ & $17(20)$ \\
$\quad$ pancreas (n=87) & & & \\
Liver (n=42) & $18(43)$ & $26(62)$ & $10(24)$ \\
Lung (n=5) & $2(40)$ & $2(40)$ & $1(20)$ \\
\hline
\end{tabular}

${ }^{*}$ Pearson $\chi^{2}$; ${ }^{\dagger}$ Coupled for analysis based on program and protocol similarities. $D$ Donor CMV serology status; R Recipient CMV serology status at time of transplantation (either positive [+] or negative [-] for CMV)

\section{Study population}

\section{RESULTS}

Between January 1, 1999, and June 30, 2000, 155 patients underwent SOT. Of these, 21 patients met the exclusion criteria, leaving a total sample size of 134 patients, of whom 58\% $(n=78)$ underwent kidney transplantations, 31\% ( $n=42)$ underwent liver transplantations, $7 \%(\mathrm{n}=9)$ underwent kidney-pancreas transplantations and $4 \%(n=5)$ underwent lung transplantations (Table 1). Two patients were lost to follow-up beyond the one-month exclusion cutoff: one patient died 59 days after transplantation and the other patient attended no further follow-up clinics after two months. Of the remaining 132 patients, 20 patients had data collected for less than six months due to transfer of care to institutions where medical records were not accessible. In these cases, all available data were used in the analysis.

The mean age of our transplant population was 46.7 years (range of 13 to 73 years) and $61 \%$ of recipients were male (Table 1). Sixty-four per cent of these transplant recipients $(n=86)$ were CMV-positive at the time of transplantation and were therefore considered to be at intermediate risk of developing CMV disease/syndrome. Only 19\% $(n=25)$ of patients were CMV mismatches and at high risk of developing primary CMV infection.

CMV disease/syndrome incidence, treatment and detection The incidence of positive CMV antigenemia, CMV disease and GCV treatment, according to pretransplantation CMV serology and transplant type, are summarized in Table 2. Over the six-month follow-up period, a total of 54 patients (40\%) had at least one positive antigenemia test result, which was defined as at least one CMV antigen-bearing cell per 200,000 PMN (Table 2). Independently, $48 \%$ of patients $(n=64)$ were classified as having CMV disease/syndrome and only $21 \%$ of patients $(n=28)$ were treated with GCV throughout follow-up. When stratified by pretransplantation CMV serology, statistically significant differences were found in the proportions of patients in each serology group that were thought to have CMV disease/syndrome and that had a positive antigenemia test result (Table 2 ). However, the difference in the proportion 
TABLE 3

Cytomegalovirus (CMV) antigenemia assay performance

\begin{tabular}{|c|c|c|c|c|c|c|c|c|}
\hline & \multicolumn{4}{|c|}{ Cutoff $\geq 1$ cell } & \multicolumn{4}{|c|}{ Cutoff $\geq 4$ cells } \\
\hline & $\begin{array}{l}R-/ D- \\
(n=22)\end{array}$ & $\begin{array}{l}R+/ D \pm \\
(n=86)\end{array}$ & $\begin{array}{l}R-/ D+ \\
(n=24)\end{array}$ & $\begin{array}{c}\text { Total } \\
(n=132)\end{array}$ & $\begin{array}{l}R-/ D- \\
(n=22)\end{array}$ & $\begin{array}{l}R+/ D \pm \\
(n=86)\end{array}$ & $\begin{array}{l}R-/ D+ \\
(n=24)\end{array}$ & $\begin{array}{c}\text { Total } \\
(n=132)\end{array}$ \\
\hline Sensitivity ${ }^{\star}, \%$ & - & 71 & 56 & 64 & - & 38 & 38 & 36 \\
\hline Positive predictive value $\ddagger$, \% & - & 76 & 75 & 76 & - & 77 & 86 & 79 \\
\hline Negative predictive value§, \% & 86 & 70 & 42 & 71 & 86 & 56 & 41 & 60 \\
\hline
\end{tabular}

${ }^{*}$ Percentage of patients with CMV syndrome/disease who are antigenemia test positive (true positive rate); ${ }^{\top}$ Percentage of patients without CMV syndrome/disease who are antigenemia test negative; ${ }^{\ddagger}$ Given positive test results - the percentage of patients with CMV syndrome/ disease; $\S$ Given negative test results - the percentage of patients without CMV syndrome/disease. D Donor CMV serology status; R Recipient CMV serology status at time of transplantation (either positive [+] or negative [-] for CMV)

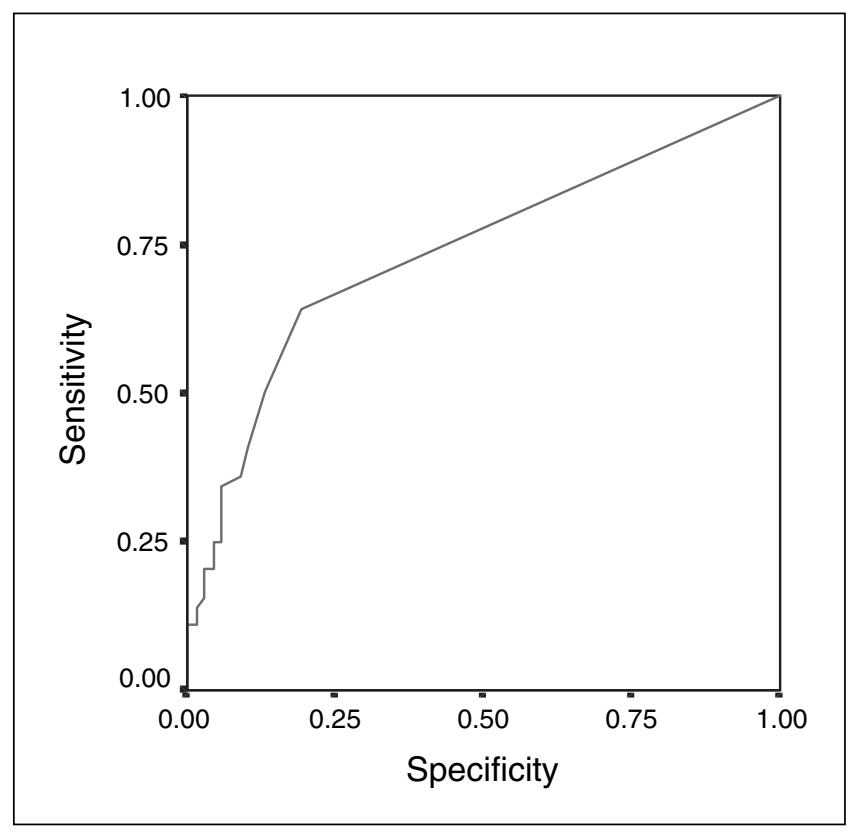

Figure 1) Receiver operating characteristic curve for maximal sensitivity and specificity. Diagonal segments were produced by ties

of patients in each serology category who were treated with GCV failed to reach statistical significance.

When stratified by transplant type, each grouping had similar proportions of patients who had at least one antigenemiapositive test result (at least one cell), and who were treated with GCV when compared with the whole population (Table 2). Liver transplant recipients, however, had a much higher rate of CMV disease/syndrome than those receiving the other transplant types, with $62 \%$ of liver transplant recipients meeting the CMV disease/syndrome criteria throughout the six-month follow-up period. Statistical analysis among these groups was not performed due to the disproportionate numbers of patients in each group; only five patients were undergoing lung transplantations, whereas the majority of patients were undergoing kidney or kidney-pancreas transplantations.

\section{Antigenemia test performance characteristics}

Performance characteristics of the antigenemia assay were analyzed using two different breakpoints (at least one cell or at least four cells) for a positive test result. This method was used to determine whether the study's protocol breakpoint of at least three to five cells improved the performance compared with a breakpoint of at least one cell. The sensitivity of the CMV antigenemia test for detecting CMV syndrome/disease was $64 \%$ and $36 \%$ when using a cutoff of at least one cell and at least four cells, respectively (Table 3 ). The specificity of a higher breakpoint led to a greater ability to detect disease-free patients; $81 \%$ and $91 \%$ specificities were found with breakpoints of at least one cell and at least four cells, respectively. Similar trends were seen when performance characteristics were determined based on baseline serology of the donor and recipient (Table 3). PPVs were similar between breakpoints of at least one cell and at least four cells (76\% and 79\%, respectively). The chances that those patients with negative test results were actually disease/syndrome negative (ie, NPV) were $71 \%$ for a cutoff of at least one cell and $60 \%$ for a cutoff of at least four cells. An ROC curve was constructed to determine the cell count at which the antigenemia test would have the greatest level of sensitivity and specificity (Figure 1). The point of inflection of the curve, which signifies maximal sensitivity and specificity, was less than one cell. However, because this could not be measured by the test, the closest measurable value of one cell was determined to be the optimal value.

Aside from the statistical parameters mentioned above, it was also evaluated whether the antigenemia test would identify patients who would go on to develop CMV disease/syndrome before the onset of symptoms. It was found that patients showed signs and symptoms of disease a mean of 18 days before antigenemia tests became positive, irrespective of the number of cells used as a cutoff for positivity (Table 4). When broken down by baseline serology, it was found that in mismatch, high-risk patients (recipient-negative/donor-positive), the test had an even poorer ability to detect disease early, and a mean of 25 to 30 days elapsed between the onset of symptoms and a positive test result. Only in $59 \%$ and $33 \%$ of patients did the antigenemia test become positive before the onset of symptoms, in which at least one cell or at least four cells were used to define a positive result, respectively (Table 4). Figure 2 illustrates the median times to onset and duration of the symptoms of CMV disease/syndrome, of positive test results and of GCV treatment throughout the six-month follow-up.

\section{Predictors of CMV disease/syndrome}

Five different variables were found to independently predict the development of CMV disease/syndrome based on univariate and multiple logistic regression models: baseline CMV serology, transplant type and the antigenemia test cutoffs of at least one, four or 10 cells. Table 5 outlines these independent predictors of CMV disease/syndrome and the calculated crude and adjusted odds ratios for these variables. The crude odds ratios 
TABLE 4

Performance characteristics of cytomegalovirus (CMV) antigenemia assay

\begin{tabular}{|c|c|c|c|c|c|c|}
\hline & \multicolumn{3}{|c|}{ Cutoff $\geq 1$ cell } & \multicolumn{3}{|c|}{ Cutoff $\geq 4$ cells } \\
\hline & $R+/ D \pm$ & R-/D+ & Total & $\mathrm{R}+/ \mathrm{D} \pm$ & $\mathrm{R}-/ \mathrm{D}+$ & Total \\
\hline $\begin{array}{l}\text { Time difference } \\
\quad(\text { mean days } \pm \mathrm{SD})^{*}\end{array}$ & $15.9 \pm 6.1$ & $25.9 \pm 14.7$ & $18.0 \pm 5.7$ & $14.3 \pm 6.3$ & $29.5 \pm 20.5$ & $18.1 \pm 6.9$ \\
\hline $\begin{array}{l}\text { Test positive before } \\
\text { symptoms (\%) }\end{array}$ & 69 & 39 & 59 & 39 & 17 & 33 \\
\hline
\end{tabular}

*Mean time difference between a positive test result (ie, at least one cell or at least four cells) and the diagnosis of CMV disease/syndrome. D Donor CMV serology status; R Recipient CMV serology status at time of transplantation (either positive [+] or negative [-] for CMV)

for developing CMV disease/syndrome for the cutoffs of at least one cell and at least 10 cells are similar: 7.5 and 7.2 times greater, respectively; however, with the cutoff of at least one cell, the confidence interval is tighter around the odds ratio, making the effect more precise. When the cutoff of at least four cells is used, the crude odds ratio is lower at 5.8.

When the multivariate model was adjusted for the antigenemia test result cutoff points, liver transplantation, having mismatch baseline serology (recipient-negative/donor-positive) and having any positive antigenemia assay results were statistically significant predictors of CMV disease/syndrome. It was also found that, in the crude model and in all adjusted models except for the cutoff of at least one cell, if the recipient was CMV-positive at baseline, then the odds ratio of developing CMV disease was significant. In the model adjusted for the cutoff of at least one cell, the strongest independent predictor of CMV disease/syndrome was the actual test result of any number of positive cells. In all other adjusted models, mismatch baseline serology (recipient-negative/donor-positive) was a stronger predictor based on odds ratios. Also included in the multivariate analysis was the $-2 \log$ likelihood measurement of how well the model fit, and the lowest value was achieved in the adjusted odds ratio for the cutoff of at least one cell.

\section{DISCUSSION}

For a disease with high morbidity and mortality, such as CMV disease, a test with a high sensitivity and PPV is optimal. However, because the treatment of suspected or confirmed CMV disease is not without the risk of adverse events or development of drug resistance, a reasonable specificity and NPV must also be maintained. For the past decade, the pp65 antigenemia assay has been used to identify CMV disease in SOT recipients, because evidence suggested this test was a sensitive method that enabled early diagnosis and pre-emptive treatment of CMV disease (12-15). In our study, we aimed to address three important questions surrounding the utility of the pp65 CMV antigenemia test in SOT recipients. First, is the test useful in predicting CMV disease/syndrome and guiding preemptive therapy? Second, does the test provide a diagnostic advantage to symptom assessment in early identification of the disease? Third, what is the optimal breakpoint to identify a positive test result?

Extensive research has been conducted evaluating the performance characteristics of multiple methods of CMV detection. Performance characteristics of CMV pp65 antigenemia testing vary widely in the literature, as may be expected with different transplant populations, laboratory methods and collection protocols. In our population of mixed organ transplantation, based on our current protocol using an at least four cell

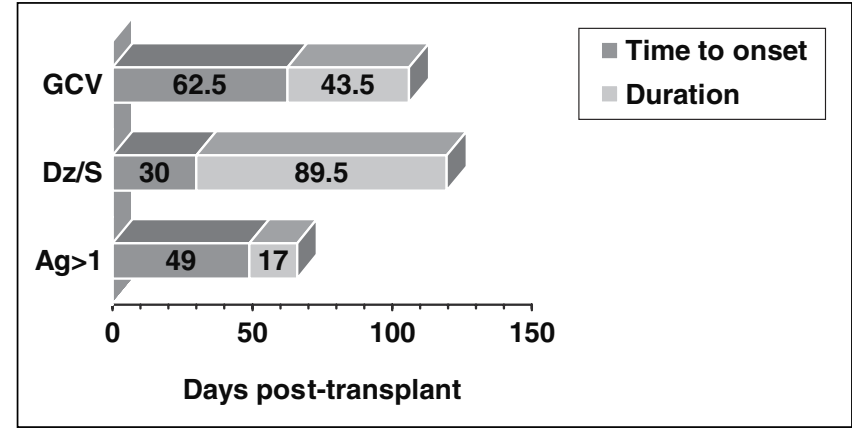

Figure 2) Median times to onset and duration of treatment, disease symptoms and test positivity. Ag $>1$ First positive cytomegalovirus pp65 test; Dz/S Cytomegalovirus disease/syndrome signs and symptoms; GCV Ganciclovir treatment (both intravenous and oral)

cutoff, sensitivity, specificity, PPV and NPV were 36\%, 91\%, $79 \%$ and $60 \%$, respectively. These values correlate with an overall rate of false positives of $9 \%$ and false negatives of $64 \%$. The sensitivity of the assay was the weakest characteristic and was similar to that evaluated in other centres $(8,16,17)$. The sensitivity of the assay was greatest in patients who were seropositive before transplantation (sensitivity of $71 \%$ ) and was also greater when the at least one cell cutoff was used to signify a positive result (sensitivity of 64\%). In general, our current antigenemia protocol did not perform well as a tool for identifying patients with CMV disease/syndrome. Other groups have, however, documented sensitivity and an NPV of $95 \%$ to $100 \%$ in liver and kidney transplant populations (18-20).

The incidence of CMV disease/syndrome in our cohort $(48 \%)$ was much greater than that reported in other studies $(7,18,19)$. The most likely explanation for our high rates of CMV infection is our decision to combine patients with both documented disease and those with CMV syndrome as previously defined (11). This decision was made based on the fact that our protocol for CMV antigenemia testing and preemptive therapy is intended to prevent CMV disease, which we believe is best accomplished by initiating therapy in selected patients who are only exhibiting signs of CMV syndrome and not necessarily active disease.

In our study, a relatively low proportion of patients were treated with GCV (21\%) compared with the number that had a positive antigenemia count throughout follow-up (40\%). GCV treatment correlated well with the $22 \%$ of patients who had an antigenemia count of at least four cells per 200,000 PMN, as our centre waits until cell counts reach between three and five cells (depending on the type of transplant) before preemptive treatment is initiated. These arbitrary breakpoints are not applicable to other transplant centres and were derived 
TABLE 5

Crude and adjusted odds ratios of independent variables for cytomegalovirus (CMV) disease/syndrome

\begin{tabular}{|c|c|c|c|c|}
\hline $\begin{array}{l}\text { Independent } \\
\text { variable }\end{array}$ & $\begin{array}{l}\text { Crude OR } \\
(95 \% \mathrm{Cl})\end{array}$ & $\begin{array}{c}\text { Adjusted OR } \\
\geq 1 \text { cell }(95 \% \mathrm{Cl})\end{array}$ & $\begin{array}{c}\text { Adjusted OR } \\
\geq 4 \text { cells }(95 \% \mathrm{Cl})\end{array}$ & $\begin{array}{c}\text { Adjusted OR } \\
\geq 10 \text { cells }(95 \% \mathrm{Cl})\end{array}$ \\
\hline \multicolumn{5}{|l|}{ Transplant type } \\
\hline Kidney and kidney-pancreas & 1.0 & 1.0 & 1.0 & 1.0 \\
\hline Liver & $2.6(1.2-5.7)$ & $3.0(1.2-7.5)$ & $2.9(1.2-6.9)$ & $3.1(1.3-7.3)$ \\
\hline \multicolumn{5}{|l|}{ Baseline serology } \\
\hline $\mathrm{R}-/ \mathrm{D}-$ & 1.0 & 1.0 & 1.0 & 1.0 \\
\hline $\mathrm{R}-/ \mathrm{D}+$ & $12.7(2.9-55.8)$ & $5.9(1.2-29.2)$ & $8.6(1.8-40.7)$ & $10.1(2.2-47.5)$ \\
\hline$\geq 1$ cell & $7.5(3.4-16.6)$ & $6.5(2.7-15.8)$ & - & - \\
\hline$\geq 4$ cells & $5.8(2.2-15.5)$ & - & $5.0(1.8-14.0)$ & - \\
\hline$\geq 10$ cells & $7.2(1.9-26.2)$ & - & - & $7.1(1.9-27.4)$ \\
\hline
\end{tabular}

D Donor CMV serology status; R Recipient CMV serology status at time of transplantation (either positive [+] or negative [-] for CMV)

based on our experience and not on consensus; therefore, for the majority of analyses, a positive result was defined as a count of at least one cell per 200,000 PMN. Of note, regardless of baseline serology, similar proportions of patients were treated with GCV. This result was unanticipated; those patients at higher risk were expected to have a higher incidence of treatment because the incidence of disease was significantly different between groups.

Other studies $(7,8,21)$ in liver and renal transplant patients have reported that CMV disease occurred anywhere from seven days before to seven days after the first positive antigenemia result. Our results were not so favourable, with signs and symptoms of CMV disease/syndrome being present a median of 18 days before antigenemia results were positive. In fact, only $59 \%$ of patients had a positive test result before the onset of CMV disease/syndrome, indicating that, despite attempts to initiate pre-emptive GCV therapy, the majority of cases were actually reactive treatment courses after the onset of disease. A study by Tong et al (8) found that only 13\% of seronegative recipients and $0 \%$ of seropositive recipients had positive antigenemia test results before disease onset, which is slightly less than our proportions of $22 \%$ and $30 \%$, respectively. Regardless of the performance characteristics calculated, if the test cannot predict disease before symptoms are present, then the clinical utility and cost-effectiveness of the tool is minimal.

In the majority of literature to date, there is a lack of standardization of antigenemia cutoffs for signifying clinically relevant disease. Although many studies have raised cutoffs in SOT patients to anywhere from 10 to 50 cells to maximize performance characteristics, our analysis supports the use of an at least one cell cutoff $(7,15,22-24)$. However, it is difficult to compare data from different centres due to methodological differences in both laboratory procedures and in definitions of CMV disease/syndrome. In our study, the inflection point of the ROC curve, which indicates maximal sensitivity and specificity of the test, was less than one cell, and the adjusted OR of 6.5 (95\% CI 2.7 to 15.8) for a cutoff of at least one cell versus an adjusted OR of 5.0 (95\% CI 1.8 to 14.0) for a cutoff of at least four cells supports the use of a one cell cutoff to represent a positive result. Similar methodology was used in a cohort of liver transplant recipients, for whom four to six cells per 150,000 PMN was the optimal cutoff (19). Despite optimizing sensitivity and specificity, these cutoffs may not improve the clinical usefulness of the antigenemia test if PPVs and early detection remain poor.
The most important limitation of our study was the use of the available definitions for CMV disease/syndrome in a retrospective manner. Clinically, the definitions provide useful criteria to guide diagnosis in a prospective fashion; however, they are general when applied to retrospective data. Some patients may have been classified inappropriately due to lack of insight into the actual clinical course of the patient. Our assessment was limited by available charting in patient records and laboratory parameters. If assessed prospectively, the impression of the clinician would have played a larger role in CMV disease/ syndrome classification, and would have likely resulted in a lower incidence of overall CMV disease/syndrome in our population; the low usage of GCV therapy, in the context of $48 \%$ of patients being classified as having CMV disease/syndrome, is likely a testament to this limitation. At the time of decision to treat, it is likely that CMV may not have been first on the list of differential diagnoses for the symptoms the patient was experiencing and the laboratory parameters collected at visits.

A further limitation to our study is that the definitions of CMV infection and disease were updated in 2002, after our study had been completed (9). Although the 1995 definitions generally hold in the updated version, an emphasis is now placed on the avoidance of PCR techniques in diagnosing CMV pneumonia and hepatitis because the test may be too sensitive and indicate a transient viremia rather than active CMV disease (9). Based on standard practice at the time of data collection, and in accordance with the 1995 definitions, some cases of CMV pneumonia or hepatitis in our study may have been confirmed using PCR techniques, further supporting the possibility of the overdiagnosis of CMV disease. Although overdiagnosis may have contributed to the discordance between GCV therapy and presumed disease, the data indicate that our current protocol of pre-emptive therapy did not adequately predict CMV disease/syndrome, and that perhaps, the use of a lower cutoff, and thus an increase in the courses of GCV given, may help to prevent more CMV disease/syndrome and, therefore, reduce its incidence. Finally, although the collection of antigenemia results and clinical data were conducted independently, reviewers were not blind to antigenemia results, which may have caused bias in the assessment of CMV disease/syndrome.

Although safer and more cost-effective than universal prophylaxis for CMV infection, our current method of pre-emptive therapy can only be successful if guided by appropriately specific and sensitive tests (7). As identified in our analysis, the pp65 antigenemia assay fails to demonstrate optimal predictive 
and performance qualities. However, although much research has been conducted comparing antigenemia testing with other quantitative assays, antigenemia is currently the most accessible, cost-effective and efficient test available at most transplant centres $(8,16,18,23)$.

With the introduction of newer and more precise methods of molecular testing, further study is needed to determine whether our current antigenemia assay can be replaced as a guide to pre-emptive GCV therapy by a more sensitive and specific test for detecting CMV viral replication at its earliest stages, thus reducing the incidence of CMV disease and preventing patient exposure to unnecessary drug therapy.

\section{REFERENCES}

1. Patel R, Snydman DR, Rubin RH, et al. Cytomegalovirus prophylaxis in solid organ transplant recipients. Transplantation 1996;61:1279-89.

2. Nichols WG, Boeckh M. Recent advances in the therapy and prevention of CMV infections. J Clin Virol 2000;16:25-40.

3. Goossens VJ, Blok MJ, Christiaans MH, Sillekens P, Middeldorp JM, Bruggeman CA. Early detection of cytomegalovirus in renal transplant recipients: Comparison of PCR, NASBA, pp65 antigenemia, and viral culture. Transplant Proc 2000;32:155-8.

4. Brennan DC. Cytomegalovirus in renal transplantation. J Am Soc Nephrol 2001;12:848-55.

5. Rubin RH, Tolkoff-Rubin NE. Antimicrobial strategies in the care of organ transplant recipients. Antimicrob Agents Chemother 1993;37:619-24

6. Limaye AP, Corey L, Koelle DM, Davis CL, Boeckh M. Emergence of ganciclovir-resistant cytomegalovirus disease among recipients of solid-organ transplants. Lancet 2000;356:645-9.

7. Kusne S, Grossi P, Irish W, et al. Cytomegalovirus pp65 antigenemia monitoring as a guide for preemptive therapy: A cost effective strategy for prevention of cytomegalovirus disease in adult liver transplant recipients. Transplantation 1999;68:1125-31.

8. Tong CY, Cuevas L, Williams H, Bakran A. Use of laboratory assays to predict cytomegalovirus disease in renal transplant recipients. J Clin Microbiol 1998;36:2681-5. (Erratum in 1999;37:881).

9. Ljungman P, Griffiths P, Paya C. Definitions of cytomegalovirus infection and disease in transplant recipients. Clin Infect Dis 2002;34:1094-7.

10. Boeckh M, Boivin G. Quantitation of cytomegalovirus: Methodologic aspects and clinical applications. Clin Microbiol Rev 1998;11:533-54.

11. Ljungman P, Plotkin SA. Workshop on CMV disease: Definitions, clinical severity scores, and new syndromes. Scand J Infect Dis 1995;(Suppl 99):87-9.

12. Erice A, Holm MA, Gill PC, et al. Cytomegalovirus (CMV) antigenemia assay is more sensitive than shell vial cultures for rapid detection of CMV in polymorphonuclear blood leukocytes. J Clin Mibrobiol 1992;30:2822-5.

13. Storch GA, Buller RS, Bailey TC, et al. Comparison of PCR and pp65 antigenemia assay with quantitative shell vial culture for detection of cytomegalovirus in blood leukocytes from solid-organ transplant recipients. J Clin Microbiol 1994;32:997-1003.

14. van den Berg AP, van der Bij W, van Son WJ, et al. Cytomegalovirus antigenemia as a useful marker of symptomatic cytomegalovirus infection after renal transplantation - a report of 130 consecutive patients. Transplantation 1989;48:991-5.

15. Kim CK, Song JH, Kim SM, et al. Clinical usefulness of human cytomegalovirus antigenemia assay after kidney transplantation. Transplantation 2003;75:2151-5.

16. Pang XL, Chui L, Fenton J, LeBlanc B, Preiksaitis JK. Comparison of LightCycler-based PCR, COBAS amplicor CMV monitor, and pp65 antigenemia assays for quantitative measurement of cytomegalovirus viral load in peripheral blood specimens from patients after solid organ transplantation. J Clin Microbiol 2003;41:3167-74.

17. Weinberg A, Hodges TN, Li S, Cai G, Zamora MR. Comparison of PCR, antigenemia assay, and rapid blood culture for detection and prevention of cytomegalovirus disease after lung transplantation. J Clin Microbiol 2000;38:768-72.

18. Seehofer D, Meisel H, Rayes N, et al. Prospective evaluation of the clinical utility of different methods for the detection of human cytomegalovirus disease after liver transplantation. Am J Transplantation 2004:4:1331-7.

19. Humar A, Gregson D, Caliendo AM, et al. Clinical utility of quantitative cytomegalovirus viral load determination for predicting cytomegalovirus disease in liver transplant recipients. Transplantation 1999;68:1305-11.

20. Degre M, Kristiansen KI, Rollag H, Holter E, Nordal KP. Detection of human cytomegalovirus (HCMV) pp67-mRNA and pp65 antigenemia in relation to development of clinical HCMV disease in renal transplant recipients. Clin Microbiol Infect 2001;7:254-60.

21. Tanabe K, Tokumoto T, Ishikawa N, et al. Comparative study of cytomegalovirus (CMV) antigenemia assay, polymerase chain reaction, serology, and shell vial assay in the early diagnosis and monitoring of CMV infection after renal transplantation. Transplantation 1997;64:1721-5.

22. Vivarelli M, De Ruvo N, Lazzarotto T, et al. Abstension from treatment of low-level pp65 cytomegalovirus antigenemia after liver transplantation: A prospective study. Transplantation 2000;70:1183-7.

23. Meyer-Koenig U, Weidmann M, Kirste G, Hufert FT. Cytomegalovirus infection in organ-transplant recipients: Diagnostic value of pp65 antigen test, qualitative polymerase chain reaction (PCR) and quantitative Taqman PCR. Transplantation 2004;77:1692-8.

24. Senechal M, Dorent R, du Montcel ST, et al. Monitoring of human cytomegalovirus infections in heart transplant recipients by pp65 antigenemia. Clin Transplant 2003;17:423-7. 


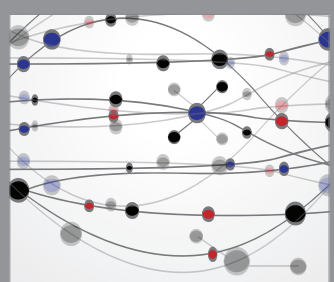

The Scientific World Journal
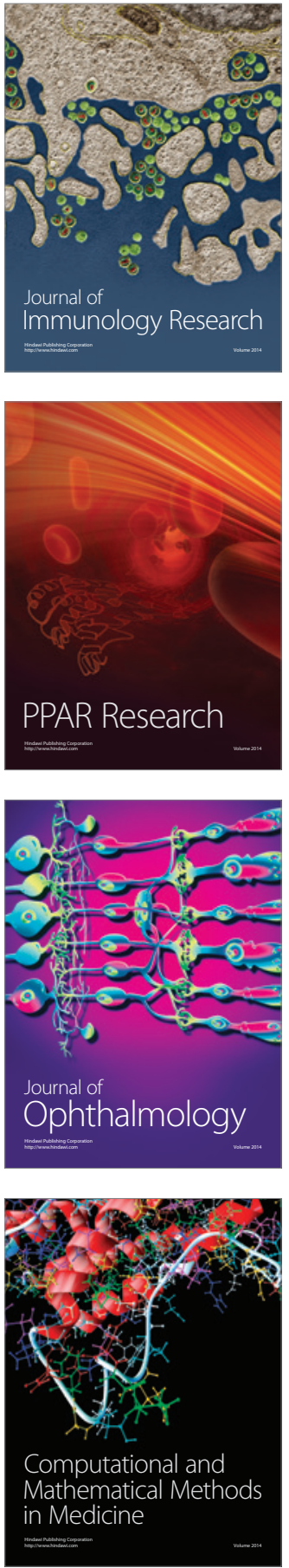

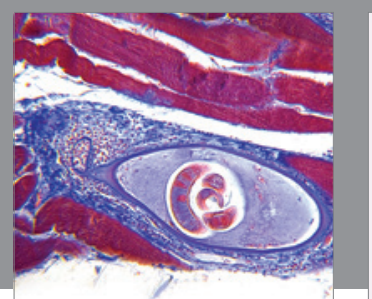

Gastroenterology Research and Practice

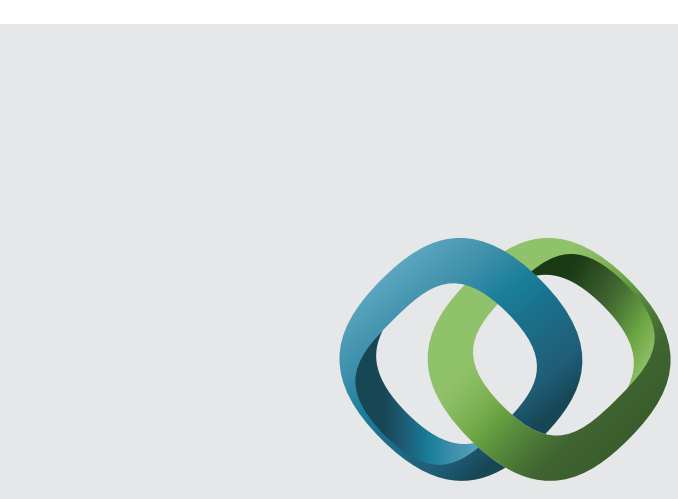

\section{Hindawi}

Submit your manuscripts at

http://www.hindawi.com
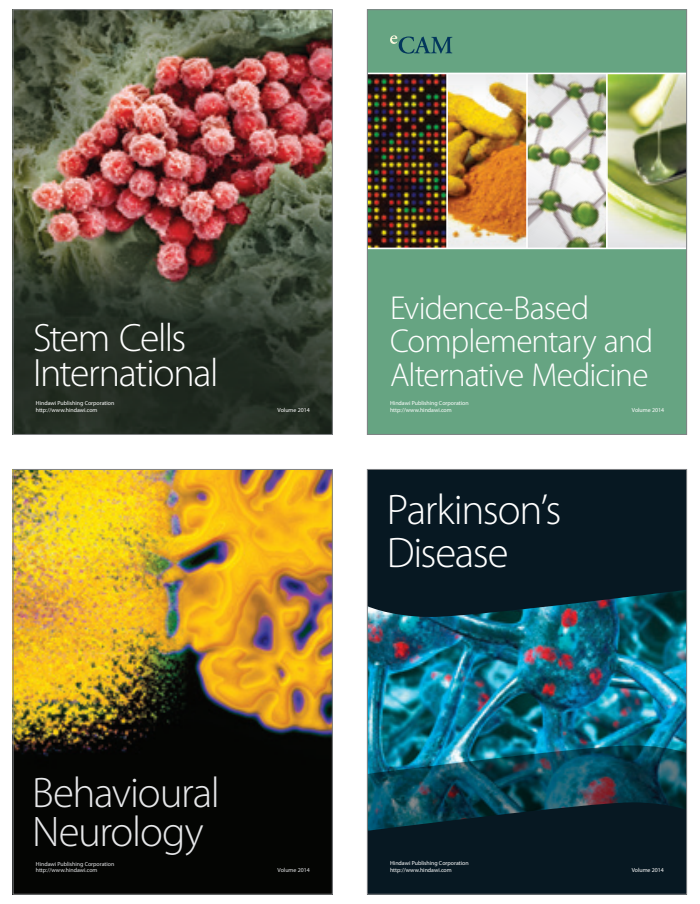
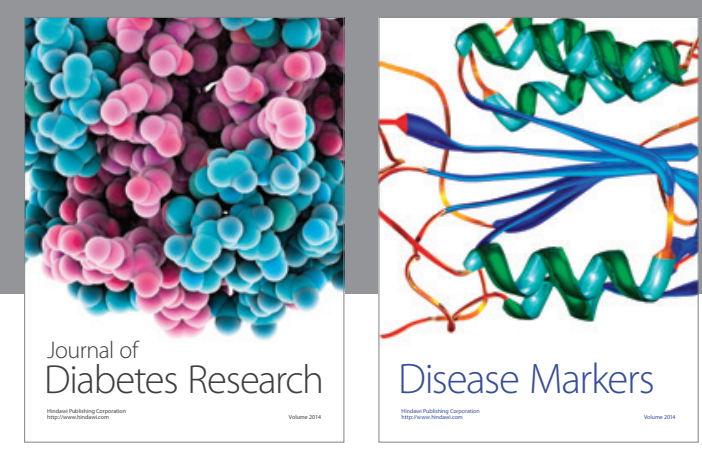

Disease Markers
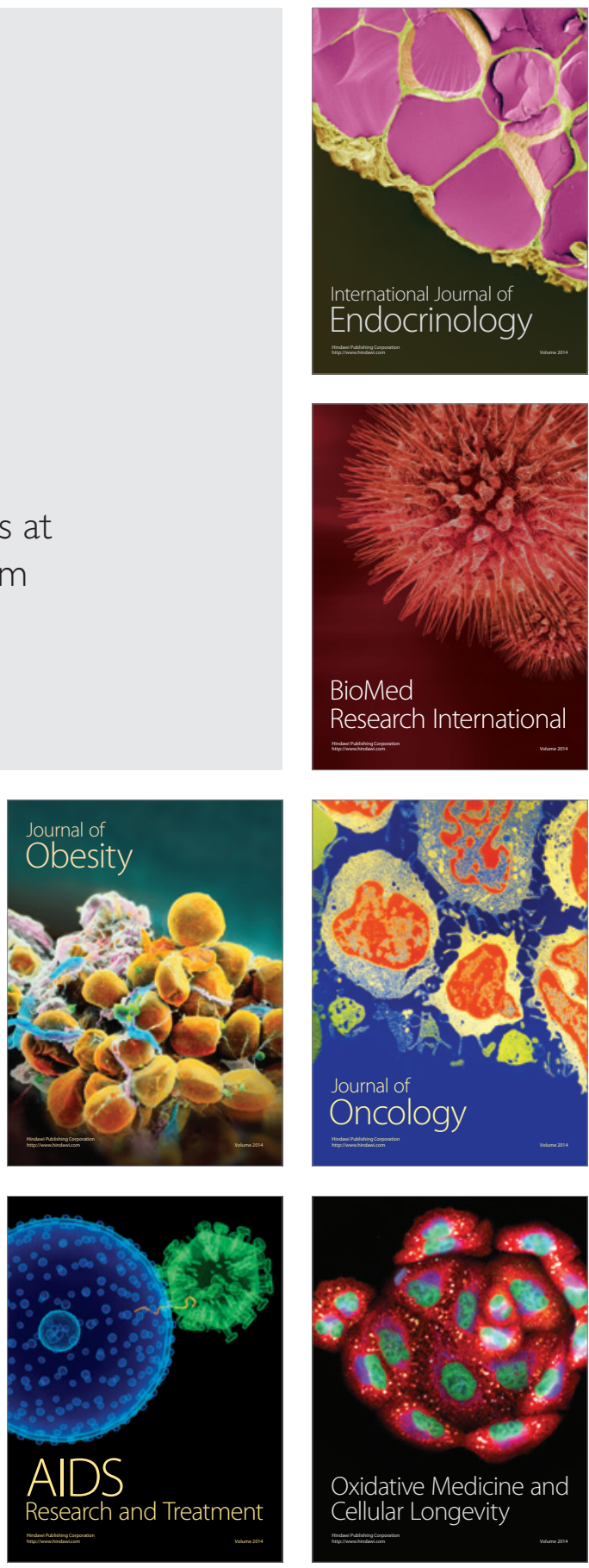